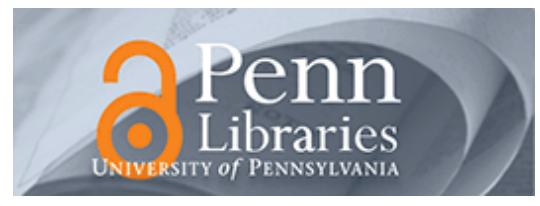

University of Pennsylvania

ScholarlyCommons

Management Papers

Wharton Faculty Research

$12-2001$

\title{
Enriching or Depleting? The Dynamics of Engagement in Work and Family Roles
}

Nancy P. Rothbard

University of Pennsylvani

Follow this and additional works at: https://repository.upenn.edu/mgmt_papers

Part of the Human Resources Management Commons, and the Organizational Behavior and Theory Commons

\section{Recommended Citation}

Rothbard, N. P. (2001). Enriching or Depleting? The Dynamics of Engagement in Work and Family Roles. Administrative Science Quarterly, 46 (4), 655-684. http://dx.doi.org/10.2307/3094827

This paper is posted at ScholarlyCommons. https://repository.upenn.edu/mgmt_papers/75

For more information, please contact repository@pobox.upenn.edu. 


\title{
Enriching or Depleting? The Dynamics of Engagement in Work and Family Roles
}

\author{
Abstract \\ This study develops a model of engagement in the multiple roles of work and family. I examine two \\ competing arguments about the effects of engaging in multiple roles, depletion and enrichment, and \\ integrate them by identifying the type of emotional response to a role, negative or positive, as a critical \\ contrasting assumption held by these two perspectives. Moreover, I represent depletion and enrichment \\ as complex multistep processes that include multiple constructs, such as engagement and emotion. This \\ study jointly examines both the depleting and enriching processes that link engagement in one role to \\ engagement in another, using structural equation modeling. Findings from a survey of 790 employees \\ reveal evidence for both depletion and enrichment as well as gender differences. Specifically, depletion \\ existed only for women and only in the work-to-family direction. Men experienced enrichment from work \\ to family, while women experienced enrichment from family to work. Overall, more linkages were found \\ between work and family for women than for men. \\ Disciplines \\ Human Resources Management | Organizational Behavior and Theory
}




\title{
Enriching or depleting? The dynamics of engagement in work and family*
}

\author{
Nancy Paige Rothbard \\ Kellogg Graduate School of Management \\ Northwestern University \\ 2001 Sheridan Road \\ Evanston, IL 60208-2001 \\ rothbard@nwu.edu \\ $847-467-3503$ \\ $847-491-8896($ fax $)$
}

April 12, 1999

*I thank Jane E. Dutton, Jeffrey R. Edwards, Robert E. Quinn, Richard P. Bagozzi, Toni Antonucci, Susan J. Ashford, Anand Swaminathan, Regina O'Neill, and Michele Williams for their helpful comments. I also thank the University of Michigan Business School for its support of this research. 


\title{
Enriching or depleting? The dynamics of engagement in work and family
}

\author{
ABSTRACT \\ Current organizational and societal trends have heightened interest in engagement in \\ multiple roles such as work and family. The work-family discourse has framed the issue in terms \\ of conflict and depletion. While acknowledging that perspective, this study challenges the \\ assumption that engagement in one role is inherently depleting to engagement in another role, \\ and suggests that multiple roles may enrich one another. The model of engagement in work and \\ family builds on and integrates the depletion and enrichment arguments by identifying the type \\ of emotional response to a role as a critical contrasting assumption held by the two perspectives. \\ Rather than assuming that engagement is depleting, this study tests how people experience \\ engagement in multiple roles. The findings indicate that while depletion does exist, stronger \\ evidence exists for enrichment. Strong gender differences were also found. Depletion existed \\ only for women and only in the work to family direction. In contrast, enrichment existed for both \\ men and women in both the work to family and the family to work directions. Overall, many \\ more linkages between work and family were found for women than for men.
}




\section{Enriching or depleting? The dynamics of engagement in work and family}

As the number of dual-earner couples and single parent families grows, people are increasingly faced with the reality of actively engaging in both work and family roles. With people's increased focus on balancing multiple life roles and managing the boundary between work and family (Hochschild, 1997; Perlow, 1998), organizations have turned to policies such as flex time, on site child care, and other mechanisms to ensure that engaging in one's family role does not interfere with one's work role. A recent Fortune article (March 17, 1997) entitled "Is your family wrecking your career?" captures well the underlying fear that engagement in family is achieved at the expense of work. The effect of family engagement on work then is an important question for managers who are interested in keeping people engaged in their work. The effect of work engagement on family is an equally important question for people making tough career choices. This study focuses on these questions and asks how engagement in one role affects engagement in another role in the context of work and family.

Two competing arguments address this phenomenon, depletion and enrichment. The depletion argument largely focuses on the fact that strain may arise from work and family roles and that conflict often emerges between the two roles (Frone, Russell, \& Cooper, 1992; Greenhaus \& Beutell, 1985). The depletion argument assumes that people have fixed amounts of psychological and physiological resources to expend and that the demands associated with work and family roles deplete these resources. Moreover, depletion assumes that people make tradeoffs in order to accommodate their fixed resources. These tradeoffs have been described as juggling (e.g., Williams et al., 1991). Moreover, researchers argue that limiting involvement in work or family will help people better achieve balance (Lambert, 1990; Yogev \& Brett, 1985). Finally, the depletion argument assumes that the multiple demands of work and family are detrimental to the individual and that role participation (whether in one or multiple roles) invokes stress, resulting in emotional strain. Research on work-family conflict and balance is framed almost entirely in terms of the depletion argument with few exceptions (e.g., Crosby, 1987; Kirchmeyer, 1992). 
The depletion argument represents a valid and important part of the story of how people's engagement in one role may relate to engagement in another role. However, because workfamily research draws primarily on the depletion perspective, it overlooks another important way that engagement in one role may relate to engagement in another role, the enrichment argument. The enrichment argument is captured by research on role accumulation and multiple roles. This argument challenges the assumptions of the depletion perspective that engagement in a role is detrimental to a person's well-being and detracts from engagement in other life roles (Marks, 1977; Sieber, 1974). In contrast to depletion, the enrichment argument suggests that a greater number of role commitments provide benefits to individuals rather than draining them. The enrichment argument assumes that these benefits outweigh the costs associated with roles leading to net gratification rather than strain. While some work-family researchers acknowledge the enrichment argument (e.g., Coverman, 1989; Williams et al, 1991), most persist in framing the problem as one of allocating fixed resources, where engagement in a role depletes resources leading to detrimental outcomes for the individual (e.g., Coverman, 1989; Tenbrunsel et al., 1995; Williams et al., 1991).

While the depletion argument captures a widespread phenomenon in terms of people's experience of work and family engagement, this paper suggests that people's engagement in work and family can be better understood by jointly examining both enrichment and depletion. The model developed here integrates these two competing arguments by articulating that a person's emotional response to a role is a central underlying aspect of both arguments. The model further specifies that it is a person's emotional response to one role that is the theoretical mechanism linking engagement in one role to engagement in another role. In addition to developing a model of engagement in work and family that incorporates emotional response as a theoretical linking mechanism, this study contributes to work-family research by empirically testing the depletion and enrichment arguments using a reciprocal model of work and family engagement. 


\section{Theoretical Framework}

In developing a model of engagement in work and family, I make two critical assumptions regarding work and family roles. First, I assume that work and family are two important life roles, which are critical to focus on in understanding how people become psychologically invested in multiple life roles. This emphasis on family rather than other nonwork roles is justified in that family has been found to be one of the most important areas in a person's life (Andrews \& Withey, 1976; Burke \& Greenglass, 1987). Second, while there are cases where work and family are too closely intertwined to be considered separate (Morf, 1989; Zedeck, 1992), I assume that the boundary between work and family is often distinguishable. Research on spillover, compensation, and work-family conflict are premised on this notion that there is a permeable yet distinguishable boundary between work and family roles such that work can influence family and family can influence work.

\section{Depletion and Enrichment}

Work-family research is dominated by the perspective that roles such as work and family bring obligations and pressures to people's lives. Research on resource drain points to the depleting aspect of life roles (Eckenrode \& Gore, 1990; Small \& Riley, 1990; Staines, 1980). Research on work-family conflict and role theory suggests that because people have finite resources, demands from one role create strain for the individual that inhibits functioning in the other role (Greenhaus \& Beutell, 1985). Essentially, work-family conflict and stress research focus on the question of how role demands and involvement increase perceived stress and strain associated with a role (e.g., Frone, et al., 1992; Kopelman, Greenhaus, \& Connolly, 1983). Strain is often conceptualized as a negative emotional response to stress such as depression or negative affect (Greenhaus \& Beutell, 1985).

While work-family conflict and role conflict research have focused on the depleting aspects of engaging in multiple roles, research on role accumulation suggests that roles may bring resources and pleasurable experiences to the person rather than strain (Sieber, 1974; 
Marks, 1977) such that roles may be enriching to one another. One proponent of the enrichment view, suggests that role participation may lead to energy expansion and points to the fact that people tend to "find" energy for things they like doing as further evidence for this perspective (Marks, 1977). From an empirical standpoint, this stream of research has focused on the effects of multiple roles on both functioning and health. First, studies of multiple roles have found that multiple role participation may enhance role engagement and functioning (Kandel, Davies, \& Raveis, 1985; Kingston \& Nock, 1992). In one study, employed wives in dual income families were found to have greater community involvement than housewives in single income families (Kingston \& Nock, 1992) suggesting that engagement in one role may enhance engagement in another role. Second, studies of multiple roles have also found that people who are involved in multiple life roles have the best health and mental well being (e.g., Baruch \& Barnett, 1986; Verbrugge, 1986), underscoring the benefits of role involvement. Thus, the findings from the enrichment perspective suggest that the benefits of role involvement may lead to gratification and a positive emotional response to the role rather than a negative emotional response or strain. Such studies have further suggested that the quality of the role experience is critical in determining whether role engagement leads to gratification or strain (Gove \& Zeiss, 1987; Verbrugge, 1986).

\section{Model of Engagement in Work and Family}

The review of the depletion and enrichment perspectives reveals that at the core of both depletion and enrichment is a contrasting assumption about a person's emotional response to a role. Depletion assumes that the multiple demands of work and family are detrimental to the individual and that participation in these roles invokes stress that results in a negative emotional response to the role. Enrichment, in contrast, assumes that roles provide benefits to the individual and that these benefits help reduce stress which results in a positive emotional response to the role. The model of engagement in work and family builds on and integrates the depletion and enrichment arguments by identifying the type of emotional response to a role as a critical contrasting assumption held by the two perspectives. Emotional response to a role refers to the 
fact that in response to role-related experiences people may feel positive or negative affect associated with the role.

Examining how a positive or negative emotional response to a role affects engagement in another role further develops the model (see Figure 1). Specifically, I suggest a person's emotional response to one role affects his or her degree of availability for and engagement in the other role. Availability refers to the degree to which people are motivated to initiate and respond to tasks and interpersonal interactions in a life role (Piotrkowski, 1979; Piotrkowski, Rapoport, \& Rapoport, 1987). Engagement in a role is defined as the attention devoted to and absorption in a role (Kahn, 1990). The model suggests that because people are more motivated to initiate and respond to tasks, greater availability increases role engagement.

\section{Insert Figure 1 about here}

The review of the depletion argument suggests that depletion is related to roles that are stressful and produce strain (Greenhaus \& Beutell, 1985; Repetti, 1987). Such stressful experiences at work may evoke negative emotions that are then transported into the family setting (Repetti, 1987). This is known as spillover. There are several theoretical explanations for why negative emotions or strain resulting from engagement in one role might reduce one's availability for and engagement in another role.

First, Scheff's (1979) theory of catharsis suggests that repressed negative emotions from one role may emerge in another role, reducing engagement in the other role. Scheff assumes that people need to discharge distressing emotions. However because culture dictates that people repress distressing emotions, tensions accumulate, causing rigid or neurotic behaviors such as emotional inexpressivity, cognitive blocks, and a lack of empathy and cooperation. Stressful experiences in one role can produce distressing emotions, which are transferred to another role, where they become manifest in the sorts of distancing behaviors that Scheff describes. For example, in one study of bank tellers, tellers noted that after a stressful day at work, they were less patient and understanding with family members (Repetti, 1987). 
Emotional distress may also decrease engagement through the discharge of emotion from one role in another role. Scheff (1979) contends that people discharge emotions through rituals, such as contests and that if these outlets are not available within a particular role, individuals may discharge their emotions in another role, pushing others away. This pattern emerges in several studies of work-family interactions (e.g., Piotrkowski, 1979; Repetti, 1987). For example, Piotrkowski (1979) found that the discharge of negative work emotions onto family members resulted in hostile interactions and emotional distance. Repetti (1987) found a similar pattern; a bank teller in her study noted that on bad work days, she would go home and snap at everyone, displacing her emotional reactions from work onto the family, pushing them away.

Self-focused attention provides a second explanation for why negative emotions from engagement in one role could reduce one's availability for and engagement in another role. Selffocused attention is thought to result from negative emotion such as depression, dissatisfaction, and frustration (Wood, Saltzberg, \& Goldsamt, 1990a; Wood et al., 1990b). Moreover, selffocused attention has been associated with a ruminative coping style (Nolen-Hoeksema, 1987; Wood et al., 1990b). When people are self-focused, they may dwell on problems from one role and be less available for and engaged in another role.

In research on work and family, there are examples of how self-focused attention serves as the mechanism linking negative emotions from one role with engagement in another role. Piotrkowski (1979) relates the story of Henry Johnson, a dispatcher for a food distribution company, who worries about work problems while at home, even waking up in the middle of the night and worrying about what might happen the next day. Henry's wife explained that his preoccupation affected the family because Henry was unable to listen to her concerns and was interpersonally unavailable due to his preoccupation with work problems. Examples of how dwelling on family problems may reduce availability for and engagement in work also exist (e.g., Crouter, 1984). In one study, an assembly line worker and mother commented “...it's hard when a kid gets sick. I worry and don't get work done well. I get ... preoccupied with worrying" 
(Crouter, 1984:431). Similarly, a male office worker stated “...when my father died last year, it made me upset. I may not have used my judgment at work" (Crouter, 1984: 432).

Self-regulation provides a third explanation for why engagement in one role, resulting in negative emotions and strain, may deplete one's availability for and engagement in another role. Self-regulation involves comparing one's current state with a standard or ideal state and adjusting to meet the standard if there is a discrepancy (Carver \& Scheier, 1981). Self-regulation is thought to deplete resources, such as energy, leaving the individual with fewer resources to cope with subsequent tasks. Baumeister, Bratslavsky, Muraven, and Tice (1998) contend that self-regulation leads to ego depletion. They explain that when people engage in volitional acts, they draw on a limited resource (akin to energy). Their findings suggest that self-regulation involves exertion, which expends energy, depleting the available supply and impairing subsequent acts of self-regulation and task performance. The experience of failure and negative emotion may serve as a signal to the self to increase self-regulation so that a person can either overcome the failure or adjust his or her standards (Greenberg \& Pyszczynski, 1986; Wood et al., 1990a). Increased self-regulation may deplete resources, resulting in fatigue (either mental or physical), making one less available for and unable to attend to the demands of another role. Work-family researchers have identified a pattern of depletion called energy deficit, which corresponds to the self-regulation explanation. For example, Piotrkowski (1979) contends that tasks that are personally depleting involve an assault on the self and that mustering one's energies for these tasks can lead to reduced availability for engaging in tasks and interpersonal interactions in another role. She describes Tony, a computer programmer, who has difficulty being interpersonally available to his family, both finding it difficult to initiate positive interactions and to respond when he is depleted from work. Repetti (1987) reports a similar pattern of experienced energy deficit where stressful experiences at work lead to little physical or emotional energy; one bank teller reported that when she comes home she just wants to be left alone and doesn't want to talk to anyone. Family factors have also been found to deplete energy 
for work engagement; a supervisor and father in Crouter's (1984: 432) study commented "when there's strife at home ... [it takes] its toll on my abilities to concentrate [at work]."

In sum, negative emotional responses resulting from engagement in one role reduce engagement in another role because negative emotions decrease availability or the degree to which an individual is motivated to initiate and respond to task and interpersonal interactions in another role. As a result of this decreased availability, people will be less engaged in the role.

\section{Hypothesis 1: Negative emotions from one role reduce engagement in the other}

role.

The enrichment approach focuses on the effects of multiple roles on functioning and health. The primary argument is that the quality of the role experience (i.e., a person's emotional response to a role) determines whether participation in a role enhances or detracts from functioning and health. Underlying these arguments is the idea that benefits associated with a role can increase an individual's sense of self-worth leading to a positive emotional response associated with that role. This positive emotional response, in turn, may increase one's engagement in the other role because one is increasingly available for the other role (Kahn, 1990; 1992). The enrichment perspective is exemplified in the work-family context by findings of positive carryover from work to family or family to work. For example, Kemper and Reichler (1976) find that among men high job satisfaction means that a worker does not bring troubles home to his family and that a positive frame of mind makes him more receptive to family needs.

Piotrkowski (1979) observes a similar pattern, which she relates through the story of Ezra Turner, a technician-supervisor at an animal lab. "At the end of the workday...Ezra was in good spirits [and felt] that the enjoyment and gratification he derives from his work extends into his relationship with his family" (Piotrkowski, 1979: 35). Piotrkowski (1979: 38) further notes that "[t]he way Ezra feels about his work induces certain types of interactions within the family system. The broad smile on his face when he came home from work suggests that he was emotionally available and therefore interpersonally available, as indicated by his high degree of involvement in family interactions."

Ezra both initiated and responded to interactions with family members and the majority of these 
interactions were affectionate, helpful, joyful, or conversational. Piotrkowski (1979:39) observes:

"few of [Ezra'] interactions were related specifically to his work. Yet we know that Ezra is gratified by what occurs there. We could suggest then, that his work experience is brought into the family system through his emotional state and his consequent interpersonal availability to family members."

Thus a person's emotional response to a role is identified as a critical factor influencing his or her interpersonal availability.

There are several explanations for why positive emotion from one role would make a person more available for another role. First, positive emotion is associated with benevolence, generosity, and increased helping toward others (Isen \& Baron, 1991), suggesting that positive emotion may make it more likely for a person to take another's perspective, making the person more available to engage in another role. Positive emotion may increase helping behaviors such as interpersonal availability and engagement because it may lead people to perceive stimuli in a more positive light (Carlson, Charlin, \& Miller, 1988) and may cause people to be more attracted to others (Bell, 1978; George, 1991).

Externally-focused attention is a second explanation for why engagement in one role, resulting in positive emotions, may increase one's engagement in another role. As was discussed in the depletion section, when people are self-focused they may dwell on problems from one role and thus may be less available for another role. In contrast, positive emotions are associated with an outward focus of attention such that when people are happy, they report increased liking for others, are more willing to initiate conversations and to offer help (M. S. Clark \& Isen, 1982; Wood et al., 1990a). As a result, being more externally focused, may increase availability, prompting individuals to initiate interactions and activities in a role. Piotrkowski's (1979: 60-61) description of Ezra Turner captures this notion of external focus.

" $[\mathrm{He}]$ derives a sense of esteem and identity from his work, and this personal gratification is made available to the family system through his ability to initiate warm and interested interactions and to respond positively to other family members. His availability "charges" family members, and he, in turn, is charged by them, thus establishing a "positive" cycle of interaction." 
The absence of self-regulation may provide a third explanation for why positive emotions resulting from one role may prompt greater engagement in another role. As discussed in the depletion section, self-regulation involves comparing one's current state with a standard and adjusting to meet the standard when there is a discrepancy (Carver \& Scheier, 1981). Selfregulation is thought to deplete resources such as energy leaving the individual with fewer resources to cope with subsequent tasks. However, positive emotions may signal that there is a lack of discrepancy between one's current and ideal state, suggesting that there is no need to selfregulate. Thus, the individual may have more resources available to attend to role requirements.

In sum, positive emotional responses from engagement in one role, may increase engagement in another role because positive emotions may increase the availability or degree to which an individual is likely to initiate and respond to task and interpersonal interactions in the other role. As a result of increased availability, individuals will be more engaged in the role.

\section{Hypothesis 2: Positive emotions from one role increase engagement in another}

role.

\section{Gender Differences}

Relationships among work and family constructs may vary by gender (e.g., Kalleberg \& Rosenfeld, 1990; Tenbrunsel et al., 1995). Research on gender role expectations suggests that observed gender differences are often a function of the divergent social roles and societal expectations for women and men (Eagly, 1987). As a result of these different roles and expectations, which people internalize into their self-concepts, women and men may develop different skills, attitudes, and behaviors perhaps through internalized gender schemas (Valian, 1998). Research on traditional gender roles suggests that as a result of gender role expectations, men tend to be agentic and act independently, whereas women tend to be expressive and act in relational ways in multiple roles (Ickes, 1993). Moreover, research on gender differences in emotion suggests that women are more emotionally expressive than men due to societal expectations regarding display rules (LaFrance \& Banaji, 1992) perhaps because high emotional expressivity by men is often evaluated negatively by others (Hammen \& Peters, 1977). Research 
on gender differences in coping suggests that men do not ruminate on emotions as much as women in part due to sex role stereotypes dictating that men are not sensitive to their emotions (Nolen-Hoeksma, 1987). While there are strong priors to suggest that gender differences do exist, it is not clear how these differences will affect the relationships among engagement in work and family. Therefore tests of gender differences in the model are conducted, but with an exploratory theory building rather than theory testing perspective.

\section{Methods}

\section{Sample and Procedure}

This study uses data collected from a larger study of work-family issues. Two waves of data were collected, the first in 1995 and the second in 1998. The current study uses data from the second wave (1998). In January of 1998 a questionnaire was sent to employees at a large public university who had responded to the 1995 work-family survey and who were still at the university in 1998. Respondents to the initial survey had been tracked by retaining names and matching identification numbers. An updated address list was obtained providing new addresses for 1,310 of the 1,758 respondents to the 1995 survey. A cover letter and questionnaire were sent to these 1,310 participants through inter-office mail. Reminder cards were sent two and a half weeks later to thank respondents and remind them to return the surveys. A lottery prize of $\$ 500$ was offered as an additional incentive to return the surveys. A total of 790 surveys were returned for a response rate of just over 60 percent. Respondents ranged in age from 23 to 70 and averaged 42 years. Just over 68\% were women, and 90\% were Caucasian. Approximately 67\% held bachelor's degrees, and 33\% had earned an advanced or professional degree. Respondents included professional and administrative staff (32.8\%), clerical workers (16.9\%), faculty (11.6\%), hospital physicians, administrators, and technicians (13.7\%), nurses (9.7\%), maintenance workers (6.4\%), and employees holding other miscellaneous positions. Compared to the initial random sample that had been stratified according to age, gender and job type, the 
final sample was about the same age, had a higher proportion of women (68\% vs. 58\%), and slightly overrepresented positions held primarily by women (e.g. clerical).

\section{Measures}

Engagement in work and family. Engagement in work and family is operationalized based on the definition of engagement as attention devoted to and absorption in work and family. Attention refers to the duration or amount of time one spends thinking about work or family and is akin to both focus of attention (Gardner, Dunham, Cummings, \& Pierce, 1989) and mental preoccupation with work and family (Frone et. al, 1992; Greenhaus \& Beutell, 1985; Lambert, 1991). Attention devoted to work or family roles is operationalized in terms of time spent thinking about and concentrating on the role. Sample items include "I focus a great deal of attention on my work "; and "I spend a lot of time thinking about my family." In total, there were 4 work attention and 4 family attention items.

The second component of role engagement is a person's absorption in a role. Unlike attention, which refers to duration of focus on a role, absorption refers to the intensity of one's focus on a role, such that one is engrossed in the role (Goffman, 1961; Kahn, 1990). The idea of flow where people do not experience themselves separately from their activities is also akin to the notion of absorption (Csikszentmihalyi, 1982; 1990). Absorption in the role is operationalized in terms of losing track of time and becoming engrossed in role performance. Sample items include: "When I am working, I often lose track of time"; and "When I am focusing on family, I am completely engrossed by it." There were 5 work absorption and 5 family absorption items.

Emotional Response to Work and Family Roles. The theoretical model of engagement in work and family builds an argument that positive emotion has one effect on engagement while negative emotion has a converse effect on engagement. Implicit in this theoretical framework is the idea that positive and negative emotion are somewhat independent responses to a situation. Evidence exists to support this conceptualization of positive and negative emotion as relatively independent of one another. For example, Watson and Tellegen's (1985) circumplex model of 
emotion portrays positive and negative affect as separate factors, which are independent of each other. They describe high positive affect as when a person is active, elated, enthusiastic, excited, peppy, and strong. High negative affect is described as distressed, fearful, hostile, jittery, nervous, and scornful. While there are other conceptualizations of positive and negative emotion, namely pleasantness/ unpleasantness, which are bipolar, the constructs of positive emotional response and negative emotional response to a role fit well with Watson and Tellegen's (1985) conceptualization of positive and negative affect. Thus, positive and negative emotional responses are operationalized as positive and negative affect associated with work and family roles. Therefore, emotional response to work and family roles is measured using the 10 item Positive Affect Negative Affect Scale (PANAS; Watson, Clark, \& Tellegen, 1988). This scale has the advantage of having been widely used in prior research.

Work and Family Importance. The importance of a role is operationalized as the centrality of the role to the person's self concept. Therefore, the importance of a role is measured with Kanungo's (1982) 6 item work centrality scale and an adapted family scale (alpha=.77 and .79 respectively in the 1995 survey). This measure has been well-established as a valid indicator of the psychological importance of a role (Blau, 1985).

Work and Family Demands. Role demands are operationalized as both quantitative time demands and as responsibility-related demands. Quantitative demands were operationalized using 1-item measuring the average amount of time required to meet role responsibilities. Responsibility-related demands were operationalized as the degree of influence demanded by one's work or family situation ( 4 items) and as the degree of flexibility required by one's work or family situation (4 items). Cronbach's alpha reliabilities for scales measuring work and family responsibility related demands were .87 and .92 in the 1995 data.

\section{Analyses}

The non recursive model of engagement in work and family was tested using structural equations modeling (SEM). Lisrel 8 was used to analyze the saturated measurement model, the structural model corresponding to the full set of hypotheses, a series of nested structural models 
testing individual hypotheses, and a series of multiple group analyses testing differences between men and women. Within the SEM approach, multiple observed indicators (i.e., scale items) are used to measure latent factors. Two composite items were created to serve as indicators of each factor following guidelines suggested by Bagozzi and Heatherton (1994).

Model fit was assessed in several ways. First, the chi-square test $\left(\chi^{2}\right)$ was used to assesses the goodness of fit between the reproduced and observed correlation matrices. However, reliance on the $\chi^{2}$ test alone is not recommended because the $\chi^{2}$ statistic is known to be sensitive to sample size (Bentler \& Bonett, 1980). Two additional fit criteria, which are not sensitive to sample size, were also used (Bentler, 1980; Gerbing \& Anderson, 1992): the comparative fit index (CFI; Bentler, 1990) and the root mean square error of approximation (RMSEA; Steiger, 1990). The CFI is the most highly recommended fit index (Bagozzi \& Edwards, 1998). While standards for this type of index are difficult to establish (Marsh, Balla, \& McDonald, 1988), values of 0.90 or greater are thought to indicate adequate fit (Bentler \& Bonett, 1980). The RMSEA, an estimate of the difference between the original and reproduced covariance matrices in the population, is another widely used fit statistic. Cudeck and Browne (1983) suggest that an RMSEA of 0.05 represents a close fit, and that an RMSEA of less than 0.08 represents a reasonable fit.

To assess the structural model, $\chi^{2}$ difference tests were used to compare the measurement model to the structural model, to determine if constraining the number of parameters estimated results in poorer fit. If it does not, then the structural model is assumed to fit as well as the measurement model. If it does result in poorer fit, other goodness of fit statistics must be examined to determine whether the structural model has a good practical fit. Next, nested models constraining paths associated with particular hypotheses were assessed to provide an omnibus test of each hypothesis. If the constrained models resulted in poorer fit, this indicates that the paths should be included as a set. Finally, parameter estimates of the structural paths were assessed to determine whether specific hypotheses were supported. 
A series of multiple group analyses were performed to test for equivalence across groups of men and women. This involved testing if differences were due to measurement error (i.e., differences in the factor loadings or error variances across groups) or to structural causes (i.e., differences in path coefficients (gammas \& betas) between men and women).

\section{Instruments}

Because this model tests a reciprocal, non-recursive relationship between work and family engagement, model identification is an important issue. A model is identified when enough information exists to generate unique parameter estimates (Berry, 1984; Bollen, 1989). A non-recursive model can be identified by incorporating at least one instrumental variable for each of the variables involved in a reciprocal relationship (Berry, 1984; James \& Singh, 1978). Therefore, in this model, several instrumental variables were included to ensure that the model was identified (Berry, 1984; James \& Singh, 1978). These instrumental variables, work and family importance and work and family demands, were chosen based on prior research. Research on job enrichment and job involvement suggests that the importance of a role increases a person's role engagement because it leads to greater internal work motivation and consequently greater effort (Brown, 1996; Hackman \& Oldham, 1980). Similarly, research on stress suggests that the demands associated with a role increase a person's engagement because demands are thought to put people into an energized state (Karasek, 1979; Karasek \& Theorell, 1990) and have been found to increase physiological arousal (Schaubroek \& Ganster, 1993).

\section{Results}

Table 1 shows means, standard deviations, correlations, and reliability estimates (calculated as Cronbach's alphas) for all scales used in the analyses. Reliabilities ranged from .77 to .95 with a median of .87 . Hence, all reliabilities exceeded the .70 criterion suggested by Nunnally (1978). The highest correlations were between like constructs such as the two components of work and family engagement respectively (i.e., work attention and absorption; 
and family attention and absorption). These high correlations are expected since these scales are thought to represent two components of an overarching construct.

Insert Table 1 about here

The saturated measurement model represents a confirmatory factor analysis of all scales used in the analysis, including the relationships between items and their factors and the correlations among the latent factors. Despite a significant chi-square statistic $\left[\chi^{2}(210)=\right.$ 615.36, $\mathrm{p}=.000$ ), which is to be expected with a sample as large as this (Bentler \& Bonett, 1980), the measurement model fit well according to the other fit statistics $(\mathrm{CFI}=.95)$ and the small size of the residuals $(\mathrm{RMSEA}=.053)$. The model also fit well according to the factor loadings since all items loaded significantly onto their intended latent factors. The measurement model also generally confirmed the idea that there was discriminant validity among the latent factors such that these factors represented distinct constructs.

The structural model represents a test of the theoretical model of engagement in work and family. As with the measurement model, while the chi-square for the structural model was significant $\left[\chi^{2}(248)=795.14, p=.000\right]$, the other fit statistics $(\mathrm{CFI}=.93)$ and the small size of the residuals $(\mathrm{RMSEA}=.057)$ indicated that the model fit the data well. Moreover, the indicators all loaded significantly on their intended factors. While the chi-square difference test indicated that the structural model fit significantly worse than the measurement model $\left[\Delta \chi^{2}(38)=179.81\right.$, $\mathrm{p}=.000]$, because the other fit indicators for the structural model suggest good practical fit of the structural model, the structural model is considered adequate (Bagozzi, 1993).

Insert Table 2 about here

The standardized path coefficients for the structural model, presented in Table 2 and Figure 2, provide partial support for the hypotheses. Table 3 reports the results of a series of constrained nested-models analyses. For each constrained model, a set of paths was fixed to zero 
to determine if unnecessary paths were included. If fit worsens significantly, this indicates that the paths dropped from the model as a set are important predictors (as hypothesized).

Insert Figure 2 about here

Hypothesis 1, which stated that negative emotions from one role would reduce engagement in the other role, was partially supported. Table 3, M1 shows that the $\chi^{2}$ increased significantly when the paths were dropped from work and family negative affect to family and work engagement respectively. This test represents an omnibus test of the paths predicted by the hypothesis as a set. However, a detailed inspection of the path coefficients in Table 2 and Figure 2 shows that work negative affect is significantly and negatively associated with family attention $(\beta=-.15, p<.01)$, but is unrelated to family absorption. Furthermore, family negative affect is unrelated to work attention, but counter to expectations, family negative affect is significantly and positively associated with work absorption $(\beta=.10, \mathrm{p}<.05)$.

Insert Table 3 about here

Hypothesis 2, which stated that positive emotions from one role would increase engagement in the other role, was not supported for work to family linkages, but was partially supported for family to work linkages. The omnibus test of the hypothesis in Table 3, M2 shows

that the $\chi^{2}$ increased significantly when the paths from work and family positive affect to family and work engagement respectively were dropped. This indicates that there were significant relationships between these latent variables as a set. However, a detailed inspection of Table 2 and Figure 2 shows that work positive affect is unrelated to either family attention or family absorption. Family positive affect is unrelated to work attention, but is significantly and positively related to work absorption $(\beta=.19, \mathrm{p}<.001)$.

\section{Gender Differences}

A series of multiple group analyses were performed to determine if the structural model of engagement in work and family differed by gender. Table 4 reports the tests of invariance between men and women in the structural model of engagement in work and family. These tests 
suggest that there are differences in several of the relationships for women and men particularly in terms of the causal relationships amongst the constructs. Figure 3 depicts the structural model for women. Figure 4 depicts the structural model for men.

Insert Table 4 about here

Differences in Betas. Figure 3 reveals that the structural model for women is very similar to the full structural model for women and men combined (Figure 2) which is not surprising given that women comprise two-thirds of the sample. In contrast, the structural model for men looks quite different from both the full model of engagement in work and family and the model for women. In contrast to these models, men experience only increased positive affect as a result of work engagement. And it is this positive affect from work that increases men's attention devoted to family. So, while for women, work attention increases both work positive and negative affect, for men it only increases work positive affect. Furthermore, while for women it is work negative affect which influences family attention, for men it is work positive affect which influences family attention. As a result, while women experience depletion from work to family via work negative affect, men experience enrichment from work to family via work $\underline{\text { positive affect. }}$

Insert Figure 3 about here

A second important difference between men and women lies in the linkages from family engagement to work engagement. For women, the attention devoted to family is positively associated with both family positive and negative affect. Women's family positive affect, in turn, is positively associated with work absorption consistent with the enrichment argument. Family negative affect is also positively associated with work absorption, consistent with a compensation explanation. However, for men, while family attention and absorption are both positively associated with family positive affect, there is no relationship between family affect and either component of work engagement. Thus, for men, there is a degree of segmentation between family and work, while there are linkages between family and work for women. 
Insert Figure 4 about here

Mean Differences Between Men and Women. While multiple group analysis tells us whether the parameter estimates differ between men and women, it does not reveal if the mean level of a latent variable differs between men and women. Exploring mean differences requires using the structured means procedure (Joreskog \& Sorbom, 1989). Table 5 reports the findings of the structured means test. The mean for women is fixed to zero and the number reported in the right column represents the change in the mean (either positive or negative) for men and whether there is a significant difference between the two groups. Table 5 reveals that men experience a lower degree of work absorption, a lower degree of family attention, lower work positive affect, higher work negative affect, and lower family positive affect than women.

Insert Table 5 about here

\section{Discussion}

This study examined the dynamics of engagement in work and family roles. Two competing arguments, depletion and enrichment were articulated and emotion was posed as a critical mediator of these relationships. Because of the strong gender role expectations associated with work and family roles, gender differences were also explored. Four critical findings emerged. First, counter to prevalent ideas, more evidence existed for enrichment than depletion. Second, strong gender differences did emerge. In particular, the role of emotion in the model differed between men and women. Third, the relationships between work and family were asymmetric; they differed depending on the direction of the relationship. Finally, there were differences in the effects of emotion on the two indicators of engagement, attention and absorption.

\section{Evidence for Enrichment and Depletion}

The findings suggest that patterns of enrichment and depletion both exist and that both gender and the direction of the relationship (i.e., work $\rightarrow$ family or family $\rightarrow$ work) matter in 
determining whether a person experiences enrichment or depletion. Overall however, there is weaker evidence for depletion. Patterns of depletion existed only for women and only in the work $\rightarrow$ family direction. One explanation for why depletion only exists for women in the work $\rightarrow$ family direction may be that as for men there are strong cultural imperatives that prevent women from ruminating on family problems at work. As a result, women like men may not allow negative emotion from family to interfere with and deplete work engagement. However, even though women may respond to the same cultural imperatives as men, they may have a different coping response. Unlike men who may compartmentalize and segment family emotions from work, women may compensate by becoming more engaged with work. This difference in response may be due to the fact that women may have more synergistic mental models of work and family roles than men (Andrews \& Bailyn, 1993; Crosby, 1991) which lead to coping in ways that are likely to integrate family and work.

These limited depletion findings also point up the possibility that women may cope differently with work negative emotions than family negative emotions. Hochschild's (1983) work on emotional labor suggests that expressing negative work-related emotion is often counter-normative for women. The effort required to suppress such emotion may use up resources that might otherwise be used for coping as described in the self-regulation, ego depletion process discussed by Baumeister et al (1998). Because the display of family emotions may not be suppressed in the same way, women may not then experience depletion from family to work, and instead they may react in an active compensatory way by becoming more engaged in another role. The above explanation is about coping and the display of emotion. A second explanation for why depletion only occurs in the work $\rightarrow$ family and not the family $\rightarrow$ work direction may be that family negative emotion simply may be more vivid and intense than work negative emotion and as such require a different coping strategy. Indeed, Hochschild (1997) suggests that negative family emotions may be more difficult to deal with than negative work emotions. Moreover, she observes that relationships at work often seem more manageable than relationships at home. As a result, women may cope with negative family emotion by using 
active coping techniques such as compensation to deliberately avoid intensely negative family emotions by engaging in work. This finding stands in contrast to the prevalent idea that strife at home limits a person's abilities to be involved in work (e.g., Crouter, 1984; Tenbrunsel et al., 1995). However, it is consistent with one of Hochschild's (1997) more controversial findings that employees seem to spend more time at work because work provides a haven from a troubled home life.

In contrast to the scarce depletion findings, strong evidence of enrichment existed for both men and women in the work $\rightarrow$ family direction and for women in the family $\rightarrow$ work direction. Even though most work-family researchers assume that depletion is the dominant pattern that exists between engagement in work and family, these findings point to the importance of examining both enrichment and depletion. One important reason for why these findings may reveal a predominant pattern of enrichment rather than depletion is that in conceptualizing and measuring engagement, this study endeavored to break free from the idea of a fixed pie. Unlike constrained constructs such as time that when expended in one role inherently deplete the other role, engagement may be enhanced by benefits of participation in a role or depleted by the costs associated with a role. In this study, the results indicate that the benefits of role participation may largely outweigh the costs such that engagement in one role is enriching to the other.

A second explanation for the predominant pattern of enrichment may be that women and men cope with negative emotion largely by reducing or avoiding its depleting effects. With one exception (women's negative work emotion) both men and women coped with negative emotion either by segmenting or compensating. In contrast, positive emotion in many cases was allowed to spill over into the other role, promoting increased role engagement. Therefore the lack of findings for depletion may be a function of how people effectively cope with negative emotions.

One further point to be raised is that for women there is a positive feedback loop from work to family and back from family to work which may represent a virtuous cycle. This has interesting implications suggesting that for women, both roles have the potential to benefit from 
one another. However, it is also important to note that depletion does exist as well, suggesting a potential dampening factor that prevents the positive feedback loop from spiraling out of control. As suggested above, one explanation for this positive feedback loop may be that women do think very synergistically about multiple roles such as work and family (Andrews \& Bailyn, 1993; Crosby, 1991). Furthermore, as Pleck (1977) suggests, the boundaries between work and family roles may be more open and permeable for women than for men such that emotions and experiences from one role affect emotions and experiences in another role very fluidly.

\section{Gender Differences}

A second critical finding concerns the strong gender differences in the model of work and family engagement. The findings reveal that many more cross-role linkages exist for women than for men. The relative plethora of linkages between work and family for women compared to the paucity of relationships between work and family for men may be explained by the idea that men may segment (or mentally separate) these roles more than women do. In support, Andrews and Bailyn (1993) found that $65 \%$ of men applied a segmented mental model to questions about work and family, whereas $67 \%$ of women used a synergistic mental model. Their results combined with Crosby's (1991) work on juggling suggest that women may evolve synergies between work and family, whereas men may view the two roles as separate and distinct.

A segmented versus synergistic mental model may affect the way a person copes with a situation in that a person's mental model represents their world view. To a person with a segmented mental model, coping by separating two roles may appear appropriate and natural. Therefore, because men may have more segmented mental models of work and family, they may find it natural to cope by segmenting work and family roles. In fact, recent views of segmentation regard it as an active coping process where people deal with stress by separating the two roles (Lambert, 1990; Piotrkowski, 1979). The view of segmentation as a coping response drawing on a particular mental model may also explain why segmentation is more prevalent for men than women in this study. 
The role of emotion in the model of engagement in work and family roles is also gendered. Certainly for women, emotion seems to be a critical mediator of the relationship between work and family. However, for men, emotion may not be as critical a mediator. It could be that the emotion-based process specified in this study may simply be more applicable to women than to men. This may be because women are more emotionally expressive than men on most emotions except for anger (Grossman \& Wood, 1993; Kring \& Gordon, 1998; see LaFrance \& Banaji, 1992 for a review). Future studies should examine specific emotions such as anger to determine if work and family are more interconnected for men via anger-based pathways. Moreover, examining emotion-based pathways in the context of work and family may also lead to these gendered conclusions because there are strong gender role expectations surrounding work and family roles. Examining emotion and engagement in the context of roles other than work and family, which may entail weaker gender expectations, would be another way to explore the validity of emotion based linkages for men in a more general model of multiple role engagement.

\section{Asymmetries}

A third important finding is the fact that work $\rightarrow$ family relationships and family $\rightarrow$ work relationships were not symmetrical. That is, support for each hypothesis depended on the direction of the relationship. For example, in some cases the hypotheses were supported in the family $\rightarrow$ work direction, but not in the work $\rightarrow$ family direction. These asymmetries suggest that work and family emotions and engagement may have different meanings across roles. Consider the case of emotions. Culturally the expression of authentic emotion may be more acceptable in the family rather than the work setting. Indeed, work is often referred to as the instrumental domain and family as the expressive domain. As a result, while family emotions may reflect opportunities for authentic self-expression, work-related emotions may be more constrained by display rules that reflect fewer opportunities for self-expression and fewer sources of intrinsic motivation. For example, Hochschild's (1983) work on flight attendants and Sutton's (1991) work on bill collectors showed that constrained display rules often exist regarding work 
emotion that can lead to inauthentic self-expression at work. As discussed above in the explanation of the limited depletion findings, because the expression and experience of emotion may be different in work and family settings, it may have different effects on engagement in the other role.

A second explanation for the asymmetries between work and family linkages is that cultural norms about what is acceptable may differ across roles and across gender. The findings for men raise interesting questions about why for men work influences family, but family does not influence work. Research on traditional gender roles contends that work is causally dominant for men (Voydanoff \& Donnelly, 1989), whereas family is dominant for women (Gutek, Searle, \& Klepa, 1991) and that the relationship between work and family differs for women and men (Gutek et al., 1991; Pleck, 1977; Tenbrunsel et al, 1995). Specifically, Pleck (1977) argues that the boundary between family and work is not as open and permeable for men as it is for women. Pleck (1977) contends that for men it is less culturally acceptable for family experiences to affect work. Because of societal expectations about gender roles, Pleck (1977) argues that the boundaries between work and family are asymmetrically permeable such that for men work affects family more than family affects work.

\section{Engagement as a Multi-Dimensional Construct}

The fourth critical finding in the study is that emotion often affected the two components of engagement -- attention and absorption -- differently. These constructs were positively correlated with one another, yet distinct. One explanation for these differences may be that attention may represent a resource-based motivational construct, whereas absorption may represent an intrinsic motivation-based construct. Attention devoted to a role may be thought of as an invisible, material resource that a person can allocate in multiple ways. As such, attention may also signal a person's availability for or capacity to perform activities in a role. In contrast to attention, which may be a resource that people have to devote to roles, absorption implies an intrinsically motivated interest in a role. In defining absorption, parallels were made to concepts like Goffman's (1961) spontaneous involvement and Csikszentmihalyi’s (1982; 1990) flow 
which indicate that absorption may represent an intrinsically motivated state. As such, absorption may also indicate availability for role activities, but for a different, more interest-based reason.

Despite these differences, the attention and absorption components of engagement are also related theoretically because they both represent motivational constructs. Attention and absorption are both attributes of motivation to act. For example, Locke and Latham (1990) refer to focused attention and intensity (the two elements of engagement) as unmeasured attributes of motivated action and as reasons for why goal mechanisms are motivational. Other motivation theories provide explanations for how resources (i.e., attention) and intrinsic interest (i.e., absorption) can both be motivating (Katzell \& Thompson, 1990). Thus, while attention and absorption are distinct components of engagement, they are both motivational mechanisms.

The different findings regarding attention and absorption in work and family also raise the issue of whether the meaning of attention and absorption is the same in the work and family roles. For example, family attention may be either people or task focused, whereas work attention may be more task-focused. As a result, family attention may have a wider range of meaning than work attention. These differences in meaning should be examined specifically in future research to better understand the concept of engagement in work and family and to better understand the relationships found in this particular study.

The different findings in terms of attention and absorption also highlight the need to measure engagement as a multi-dimensional construct. For example, if this study had only examined attention, we may have concluded solely that work engagement is depleting to family engagement for women and that family engagement does not affect work engagement for women and men. Instead, by examining absorption as well as attention, the rich interconnections and complex relationships between work and family emerged revealing both enrichment and depletion stories.

\section{Limitations}

The study's findings should be considered in light of its limitations. First, while the study tests a non-recursive feedback model, these analyses are limited by the use of cross-sectional 
data. The few studies that also examine the reciprocal effects of work on family have also been conducted using cross-sectional data (e.g., Kalleberg \& Rosenfeld, 1990; Tenbrunsel et al., 1995); however, the findings presented in this study should be interpreted with caution and taken to be initial indicators of the dynamic relationships between work and family. Future research should examine longitudinal panel data collected at several points in time.

Second, consistent with some work-family research (e.g., Duxbury \& Higgins, 1991; Kalleberg \& Rosenfeld, 1990; Tenbrunsel et al., 1995), the findings indicate strong differences between women and men. Overall, the full model of engagement in work and family roles seems to be more applicable to women than to men. These findings limit the generalizability of the model to some extent. The powerful nature of these gender differences suggests that future studies of engagement in work and family as well as other types of multiple roles should explore these gender differences more thoroughly. Such research may reveal important distinctions between the ways that men and women experience engagement in multiple roles. Exploring specific emotions such as anger may also be useful and may help clarify if the male segmentation model holds for all emotions or if depletion or compensation also occur when men experience anger rather than sadness or anxiety in work and family.

A third limitation is the use of only self-report survey data and the resulting problem of common method, common source variance. Common method variance refers to potential error that may contaminate both measures in a similar way such that a correlation between two measures may be due to the fact that both come from the same source, rather than a substantive relationship between them. However, since this model focuses on people's perceptions of their engagement, emotion, and other factors, responses from the individuals themselves are needed. The pattern of findings also diminishes concerns about common method bias. For example, the two components of engagement, attention and absorption, had different relationships with predictor and outcome variables. Furthermore, Spector (1987) suggests that method variance is more of a problem with single item or poorly designed scales and less of a problem with multi- 
item scales that are well-designed. That most of the measures in this study were multi-item scales with high reliabilities also diminishes this concern.

\section{Contributions}

Despite these limitations, this study makes several theoretical contributions. First, it contributes to work-family research by challenging the dominant view that engagement in one role is inherently depleting to another role. Instead, it offers an alternative, the enrichment perspective, which has been articulated in research on multiple roles, as a counterpoint to depletion. The findings support the notion that enrichment is an important perspective that helps illuminate the complex dynamics between engagement in work and family roles.

Second, this study contributes to both work-family and role engagement theory by specifying an emotion-based process by which engagement in one role relates to engagement in another role. By examining the depletion and enrichment perspectives jointly, this study highlights the central role of emotion as a linchpin connecting engagement in work and family. Furthermore, by articulating the role of emotion, it identifies a way to integrate these two competing arguments.

Third, this study contributes to work-family and job involvement research by breaking free of an inherently constrained notion of involvement in work and family roles. By articulating

and examining the construct of engagement, which is not an inherently fixed quantity, this study tests a fuller range of assumptions about work and family dynamics. Future studies should also examine work and family dynamics using unconstrained constructs such as engagement.

\section{Practical Implications}

Assumptions about engagement in multiple roles abound suggesting that tradeoffs and sacrifices must be made to achieve success in a particular role (e.g., Lambert, 1990). This study provides a strong counterpoint to these assumptions by revealing the potential for enrichment. The findings suggest that for women there may be benefits to building a richer family life with the notion that it may not deplete work, but may in fact enrich it. These findings further imply that working women with rich family lives should feel less guilty about being highly engaged in 
family life because, contrary to popular belief, high family engagement may not have depleting effects on work and in fact may enrich work instead. While the findings show that for women work may deplete family engagement somewhat, it is encouraging to see that there is also the potential for enrichment from work to family and from family to work. This sentiment is similar to Faye Crosby's (1991) idea that jugglers often feel both exhilarated and overwhelmed by the reality of multiple roles. While depletion does exist, the potential for enrichment is also strong and seems more likely to dominate in the family $\rightarrow$ work direction.

The findings also suggest that for men there were few interconnections between work and family perhaps because of cultural expectations and perhaps because men have more segmented mental models of the two roles. These findings imply that the lack of connections between the two roles may be not be detrimental given that it seems to protect men from depletion. Given that a segmented coping style may be nurtured by gender role expectations and congruent with the cultural milieu of the work world, this segmented style may be highly functional. However, the findings do suggest some potential drawbacks of this style in that, at a mean level, women were more absorbed in work and more attentive to family than men. This may indicate that men may be missing out on opportunities for enrichment especially from family to work that could increase their work engagement. Specifically, if men were able to benefit from the enriching potential of family life, they might be able to increase their focus on work, which could potentially increase their work productivity.

For organizations, the study's findings are quite encouraging. Far from confirming the fears expressed in articles such as the Fortune article, "Is your family wrecking your career?" these findings suggest that for men, family is not negatively affecting work engagement and that for women, family is enhancing work engagement via both positive and negative family emotion. These findings also suggest that rather than trying to limit family commitments and role participation, that organizations may do well to encourage such activities as people may gain energy from them. 


\section{Conclusion}

Current organizational and societal trends have heightened the interest in engagement in multiple roles such as work and family. The discourse in work-family research has framed the problem as one of conflict and depletion. This study challenges that assumption and builds on multiple roles research to suggest that multiple roles may be enriching to one another. Furthermore, this study builds a theoretical model that accounts for these two competing arguments, depletion and enrichment, and explains how people experience engagement in multiple roles. In contrast to many of the assumptions in work-family research, the findings here indicate that there is stronger evidence that engagement in multiple roles can be enriching rather than depleting. As a result, this study suggests that the work-family conflict discourse should be reframed to consider the enriching, replenishing effects of multiple roles. Future research must consider the enrichment perspective and identify opportunities for replenishment and enrichment. 


\section{References}

Andrews, A., \& Bailyn, L.

1993. " Segmentation and synergy: Two models linking work and family." In J. C. Hood (Ed.), Men, Work, and Family. Newbury Park, CA: Sage Publications.

Andrews, F. M., \& Withey, S. B.

1976. Social Indicators of Well-being: America’s Perception of Life Quality. New York: Plenum Press.

Bagozzi, R. P.

1993. "Assessing construct validity in personality research: Applications to measures of selfesteem." Journal of Research in Personality, 27 (1): 49-87.

Bagozzi, R. P. \& Edwards, J. R.

1998. "A general approach for representing constructs in organizational research." Organizational Research Methods, 1 (1): 45-87.

Bagozzi, R. P., \& Heatherton, T. F.

1994. "A general approach to representing multifaceted personality constructs: Application to state self-esteem." Structural Equation Modeling, 1: 35-67.

Baruch, G. K. \& Barnett, R.

1986. "Role quality, multiple role involvement, and psychological well-being in midlife women." Journal of Personality and Social Psychology, 51 (3): 578-585.

Baumeister, R.F., Bratslavsky, E., Muraven, M. \& Tice, D.M.

1998. "Ego depletion: Is the active self a limited resource?" Journal of Personality and Social Psychology, 74 (5): 1252-1265

Bell, P. A.

1978. "Affective state, attraction, and affiliation: Misery loves happy company too." Personality and Social Psychology Bulletin, 4: 616-619.

Bentler, P. M. 
1980. "Multivariate analysis with latent variables: Causal modeling." Annual Review of Psychology, 31: 419-456.

Bentler, P. M.

1990 . "Comparative fix indexes in structural models." Psychological Bulletin, 107: 238-246.

Bentler, P. M., \& Bonett, D. G.

1980. "Significance tests and goodness of fit in analysis of covariance structures."

Psychological Bulletin, 88: 588-606.

Berry, W. D.

1984. Nonrecursive causal models. Beverly Hills, CA: Sage Publications.

Blau, G.

1985. "A multiple study investigation of the dimensionality of job involvement." Journal of Vocational Behavior, 27: 19-36.

Bollen, K. A.

1989. Structural Equations with Latent Variables. New York: John Wiley \& Sons.

Brown, S. P.

1996. "A meta-analysis and review of organizational research on job involvement." Psychological Bulletin, 120(2): 235-255.

Burke, R. J., \& Greenglass, E.

1987. "Work and family." In C. L. Cooper \& I. T. Robertson (Eds.), International review of industrial and organizational psychology: 273-320. New York: Wiley.

Carlson, M., Charlin, V., \& Miller, N.

1988"Positive mood and helping behavior. A test of six hypotheses." Journal of Personality and Social Psychology, 55 (2): 211-229.

Carver, C. S., \& Scheier, M. F.

1981. Attention and self-regulation: A control theory approach to human behavior. New York: Springer-Verlag.

Clark, M. S., \& Isen, A. M. 
1982. "Toward understanding the relationship between feeling states and social behavior." In A. Hastorf \& A. M. Isen (eds.), Cognitive Social Psychology, pp. 73-108. New York: Elsevier. Coverman, S.

1989. "Role overload, role conflict, and stress: Addressing consequences of multiple role demands." Social Forces, 67 (4): 965-982.

Crosby, F., (ed).

1987. Spouse, Parent, Worker: On Gender and Multiple Roles. New Haven: Yale University Press.

Crosby, F.

1991. Juggling: The unexpected advantages of balancing career and home for women and their families. New York: Free Press.

Crouter, A. C.

1984. "Spillover from family to work: The neglected side of the work-family interface." Human Relations, 37: 425-441.

Cudeck, R., \& Browne, M. W.

1983. "Cross-validation of covariance structures." Multivariate Behavioral Research, 18: 147167.

Czikszentmihalyi, M.

1982. Beyond bordom and anxiety. San Francisco: Jossey-Bass.

Czikszentmihalyi, M.

1990. Flow: The psychology of optimal experience. New York: Harper \& Row, Publishers.

Duxbury, L. E., \& Higgins, C. A.

1991. "Gender differences in work-family conflict." Journal of Applied Psychology, 76 (1): 6074.

Eagly, A. H.

1987. Sex differences in social behavior: A social-role interpretation. Hillsdale, NJ: L. Erlbaum Associates. 
Eckenrode, J., \& Gore, S.

1990. Stress between work and family. New York: Plenum Press.

Frone, M. R., Russell, M., \& Cooper, M. L.

1992. "Antecedents and outcomes of work-family conflict: Testing a model of the work-family interface." Journal of Applied Psychology, 77: 65-78.

Gardner, D. G., Dunham, R. B., Cummings, L. L., \& Pierce, J. L.

1989. "Focus of attention at work: Construct definition and empirical validation." Journal of Occupational and Organizational Psychology, 62: 61-77.

George, J. M.

1991. "State or trait: Effects of positive mood on prosocial behaviors at work." Journal of Applied Psychology, 76 (2): 299-307.

Gerbing, D. W., \& Anderson, J. C.

1992. "Monte carlo evaluations of goodness of fit indices for structural equations models." Sociological Methods and Research, 21: 132-160.

Goffman, E.

1961. Encounters: Two studies in the sociology of interaction. Indianapolis: Bobbs-Merrill Co.

Gove, W. R., \& Zeiss, C.

1987. "Multiple roles and happiness." In F. Crosby (ed). Spouse, Parent, Worker: On Gender and Multiple Roles: 125-137. New Haven: Yale University Press.

Greenberg, J., \& Pyszcsynski, T.

1986. "Persistent high self-focus after failure and low self-focus after success: The depressive self-focusing style". Journal of Personality and Social Psychology, 50: 1039-1044.

Greenhaus, J. H., \& Beutell, N. J.

1985. "Sources of conflict between work and family roles." Academy of Management Review, $10(1), 76-88$.

Grossman, M., \& Wood, W. 
1993. "Sex differences in intensity of emotional experience: A social role interpretation." Journal of Personality and Social Psychology, 65 (5): 1010-1022.

Gutek, B. A., Searle, S., \& Klepa, L.

1991. "Rational versus gender role explanations for work-family conflict." Journal of Applied Psychology, 76: 560-568.

Hackman, J. R., \& Oldham, G. R.

1980. Work redesign. Reading, MA: Addison-Wesley.

Hammen, C. L., \& Peters, S. D.

1977. "Differential responses to male and female depressive reactions." Journal of Consulting \& Clinical Psychology, 45 (6): 994-1001.

Hochschild, A. R.

1983. The managed heart: Commercialization of human feeling. Berkeley: University of California Press.

Hochschild, A. R.

1997. The Time Bind: When work becomes home and home becomes work. New York: Metropolitan Books.

Ickes, W.

1993. "Traditional gender roles: Do they make and then break, our relationships?" Journal of Social Issues, 49 (3): 71-85.

Isen, A. M., \& Baron, R. A.

1991. "Positive affect as a factor in organizational behavior." Research in Organizational Behavior, 13: 1-53.

James, L.R., \& Singh, B.K.

1978. "An introduction to the logic, assumptions, and basic analytic procedures of two-stage least squares.” Psychological Bulletin, 85: 1104-1122.

Joreskog, K. G., \& Sorbom, D.

1989. "LISREL 7: User's reference guide." Chicago, Scientific Software International, Inc. 
Kahn, W. A.

1990. "Psychological conditions of personal engagement and disengagement at work." Academy of Management Journal, 33(4): 692-724.

Kahn, W. A.

1992. "To be fully there: Psychological presence at work." Human Relations, 45(4): 321-349.

Kalleberg, A. L., \& Rosenfeld, R. A.

1990. "Work in the family and in the labor market: A cross-national, reciprocal analysis." Journal of Marriage and the Family, 52: 331-346.

Kandel, D. B., Davies, M., Raveis, V. H.

1985. "The stressfulness of daily social roles for women: Marital, occupational and household roles." Journal of Health and Social Behavior, 26: 64-78.

Kanungo, R. N.

1982. "Measurement of job and work involvement." Journal of Applied Psychology, 67(3): 341-349.

Karasek, R. A.

1979. "Job demands, job decision latitude, and mental strain: Implications for job redesign." Administrative Science Quarterly, 24: 285-308.

Karasek, R. A., \& Theorell, T.

1990. Healthy work: Stress, productivity, and the reconstruction of working life. New York: Basic Books.

Katzell, R. A., \& Thompson, D. E.

1990. Work motivation: Theory and practice. American Psychologist, 45 (2): 144-153.

Kemper, T. D., \& Reichler, M. L.

1976. "Work integration, marital satisfaction, and conjugal power." Human Relations, 29: 929944.

Kingston, P. W., \& Nock, S. L. 
1992."Couples' joint work status and community and social attachments." Social Science Quarterly, 73(4): 862-875.

Kirchmeyer, C.

1992. "Nonwork participation and work attitudes: A test of scarcity vs expansion models of personal resources." Human Relations, 45 (8): 775-795.

Kopelman, R., Greenhaus, J., \& Connolly, T.

1983. "A model of work, family, and interrole conflict: A construct validation study." Organizational Behavior and Human Performance, 32: 198-215.

Kring, A. M., \& Gordon, A. H.

1998. "Sex differences in emotion: Expression, experience, physiology." Journal of Personality and Social Psychology, 74 (3): 686-703.

LaFrance, M., \& Banaji, M.

1992. "Toward a reconsideration of the gender-emotion relationship." In M. S. Clark (Ed.), Emotion and Social Behavior. Newbury Park, CA: Sage Publications.

Lambert, S. J.

1990. "Processes linking work and family: A critical review and research agenda." Human Relations, 43: 239-257.

Lambert, S. J.

1991. "The combined effects of job and family characteristics on the job satisfaction, job involvement, and intrinsic motivation of men and women workers." Journal of Organizational Behavior, 12: 341-363.

Locke, E. A., \& Latham, G. P.

1990. A theory of goal setting and task performance. Englewood Cliffs, NJ: Prentice Hall.

Marks, S. R.

1977. " Multiple roles and role strain: Some notes on human energy, time, and commitment." American Sociological Review, 42: 921-936.

Marsh, H. W., Balla, J. R., \& McDonald, R. P. 
1988. "Goodness-of-fit indexes in confirmatory factor analysis: The effect of sample size." Psychological Bulletin, 103: 391-410.

Morf, M.

1989. The work/life dichotomy. Westport, CT: Quorum Books.

Nolen-Hoeksema, S.

1987. "Sex differences in unipolar depression: Evidence and theory." Psychological Bulletin, 101: 259-282.

Nunnally, J. C. (1978). Psychometric Theory. New York: McGraw-Hill.

Perlow, L. A.

1998. "Boundary Control: The social ordering of work and family time in a high-tech corporation." Administrative Science Quarterly, 43: 328-357.

Piotrkowski, C. S.

1979. Work and the family system. New York: Free Press.

Piotrkowski, C. S., Rapoport, R. N., \& Rapoport, R.

1987. "Families and work." In M. Sussman \& S. Steinmetz (Eds.), Handbook of marriage and the family (pp. 251-283). New York: Plenum.

Pleck, J. H.

1977. "The work-family role system." Social Problems, 24 (4): 417-427.

Repetti, R. L.

1987. "Linkages between work and family roles." Applied Social Psychology Annual, 7: 98-127.

Schaubroeck, J., \& Ganster, D. C.

1993. "Chronic demands and responsivity to challenge." Journal of Applied Psychology, 78 (1): 73-85.

Scheff, T. J.

1979. Catharsis in healing, ritual, and drama. Berkeley, CA: University of California Press.

Sieber, S. D.

1974. "Toward a theory of role accumulation." American Sociological Review, 39(4): 567-578. 
Small, S. A., \& Riley, D.

1990. "Toward a multidimensional assessment of work spillover." Journal of Marriage and the Family, 52: 51-61.

Spector, P. E.

1987. "Method variance as an artifact in self-reported affect and perceptions at work: Myth or significant problem?" Journal of Applied Psychology, 72 (3), 438-443.

Staines, G. L.

1980. "Spillover versus compensation: A review of the literature on the relationship between work and nonwork." Human Relations, 33: 111-129.

Steiger, J. H.

1990. " Structural model evaluation and modification: An interval estimation approach." Multivariate Behavioral Research, 25: 173-180.

Sutton, Robert I.

1991. "Maintaining norms about expressed emotions: The case of bill collectors." Administrative Science Quarterly, 36 (2): 245-268.

Tenbrunsel, A. E., Brett, J. M., Maoz, E., Stroh, L. K., \& Reilly, A. H.

1995. "Dynamic and static work-family relationships." Organizational Behavior and Human Decision Processes, 63: 233-246.

Valian, V.

1998. Why so slow? The advancement of women. Cambridge: MIT Press.

Verbrugge, L. M.

1986. "Role burdens and physical health of women and men." Women and Health, 11 (1): 4777.

Voydanoff, P., and Donnelly, B. W.

1989. "Work and family roles and psychological distress." Journal of Marriage and the Family, 51: 923-932.

Watson, D., Clark, L. A., \& Tellegen, A. 
1988. "Development and validation of brief measures of positive and negative affect: The PANAS scales." Journal of Personality and Social Psychology, 54 (6): 1063-1070. Watson, D., \& Tellegen, A.

1985. "Toward a consensual structure of mood." Psychological Bulletin, 98 (2): 219-235.

Williams, K. J., Suls, J., Alliger, G. M., Learner, S. M., \& Wan, C. K.

1991. "Multiple role juggling and daily mood states in working mothers: An experience sampling study." Journal of Applied Psychology, 76 (5): 664-674.

Wood, J. V., Saltzberg, J. A., Golsamt, L. A.

1990a. "Does affect induce self-focused attention?" Journal of Personality and Social Psychology, 58 (5): 899-908.

Wood, J. V., Saltzberg, J. A., Neale, J. M., Stone, A. A., \& Rachmiel, T. B.

1990b. "Self-focused attention, coping responses, and distressed mood in everyday life." Journal of Personality and Social Psychology, 58 (6): 1027-1036.

Yogev, S. \& Brett, J.

1985 "Patterns of work and family involvement among single- and dual-earner couples." Journal of Applied Psychology, 70 (4): 754-768.

Zedeck, S. (Ed.).

1992. Work, families, and organizations. San Francisco: Jossey-Bass. 
Figure 1

Theoretical Wodel of Engagement in Work and Family

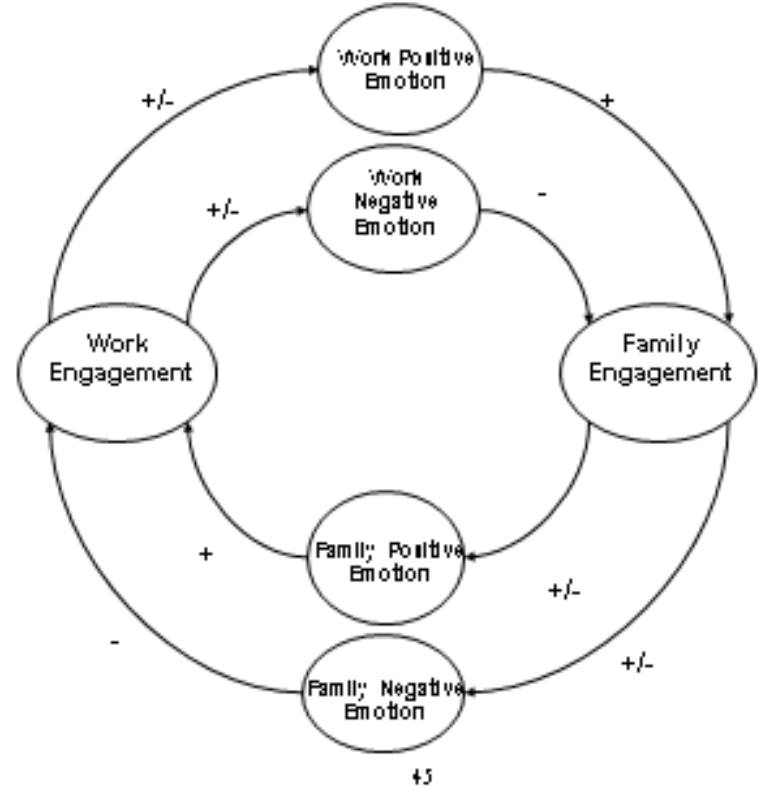


Figure 2

Results of Full Structural Model

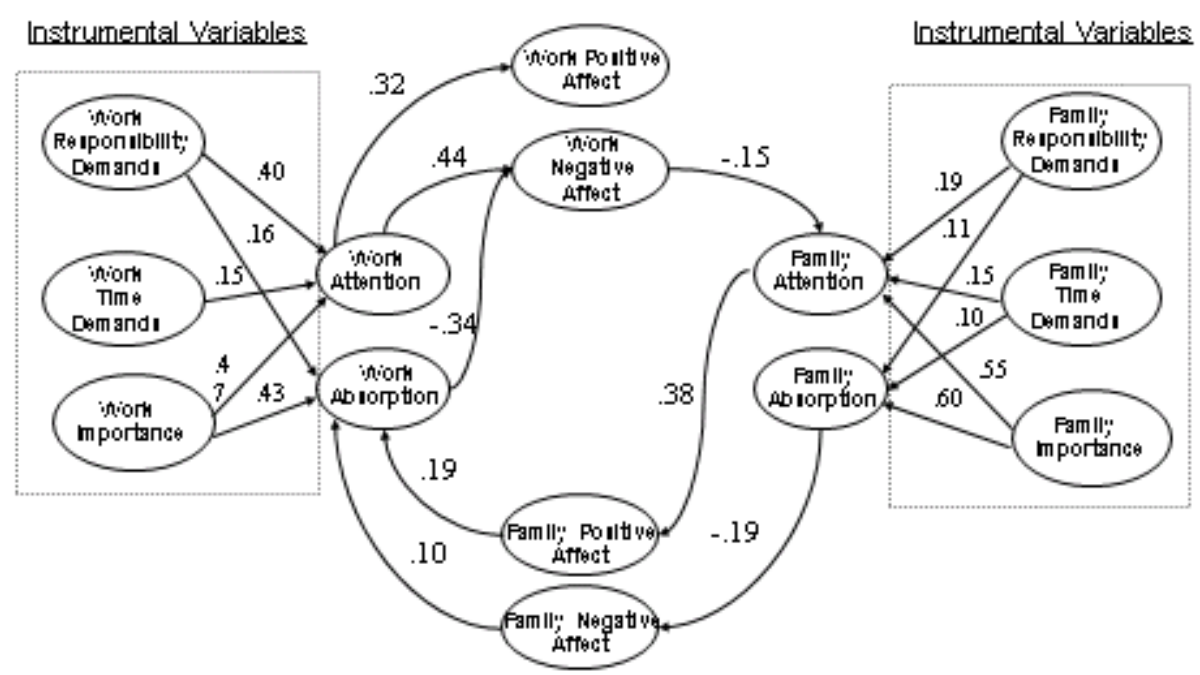

Note that allpaths included on the ngre are sigumcartat $p=D 5$ 
Figure 3

Results of Structural Model for Women

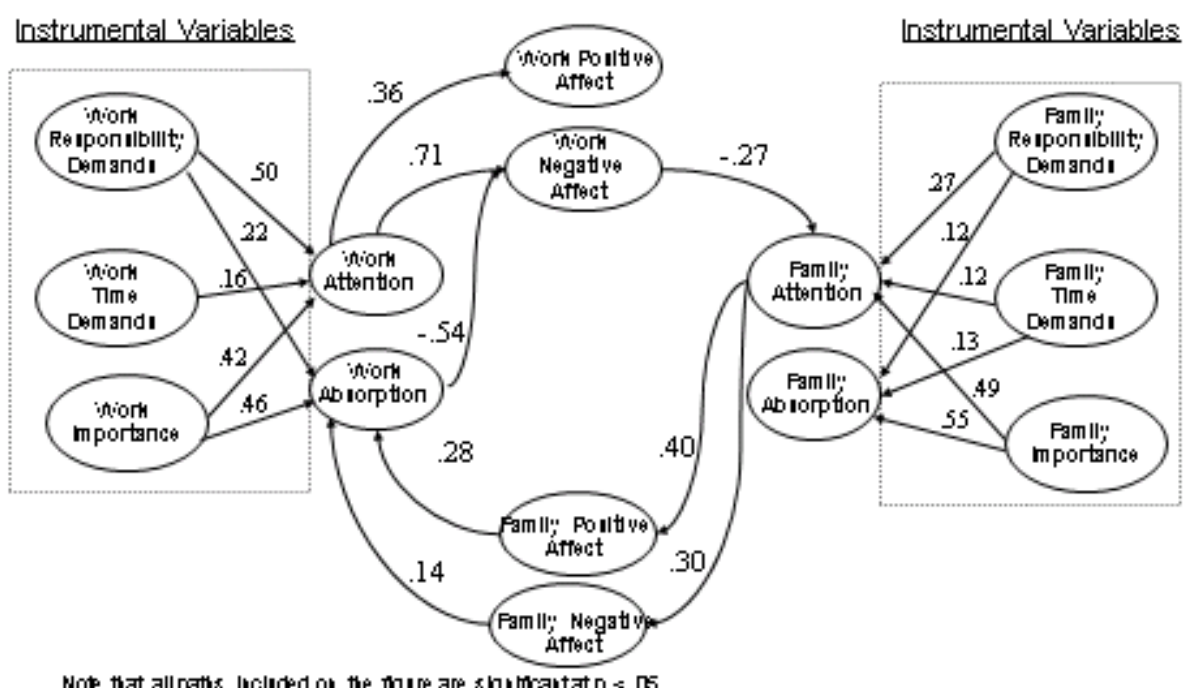

47 
Figure 4

Results of Structural Model for Men

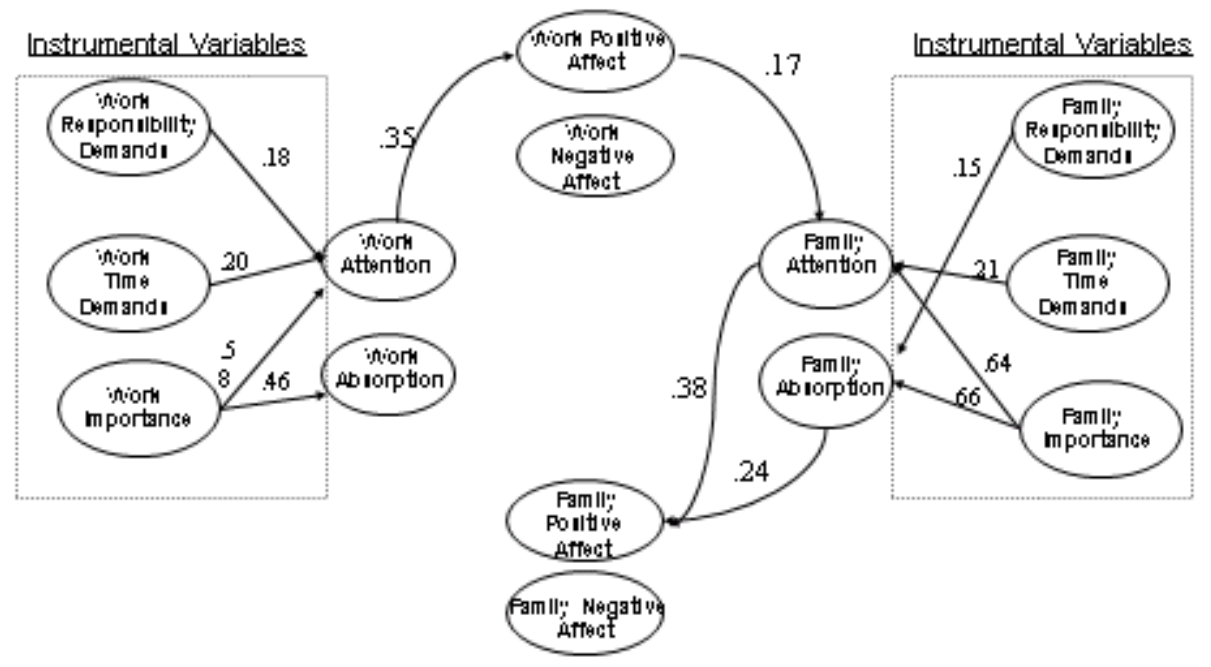

Note that allpaths licioded on the ngure are sigumcartat $p=D 5$ 
Table 1

Descriptive Statistics of All Scales Used in Analyses

\begin{tabular}{|c|c|c|c|c|c|c|c|c|c|c|c|c|c|c|c|c|}
\hline & Mean & s.d. & 1 & 2 & 3 & 4 & 5 & 6 & 7 & 8 & 9 & 10 & 11 & 12 & 13 & 14 \\
\hline 1. Work Attention & 5.75 & 1.01 & $(.78)$ & & & & & & & & & & & & & \\
\hline 2. Work Absorption & 4.70 & 1.02 & .56 & $(.78)$ & & & & & & & & & & & & \\
\hline 3. Family Attention & 5.82 & 1.03 & .12 & .09 & $(.87)$ & & & & & & & & & & & \\
\hline 4. Family Absorption & 4.48 & 1.16 & .06 & .28 & .52 & $(.80)$ & & & & & & & & & & \\
\hline 5. Work Responsibility Demands & 4.47 & 1.21 & .23 & .18 & .05 & .05 & $(.88)$ & & & & & & & & & \\
\hline 6. Work Quantitative Demands & 45.44 & 13.09 & .20 & .12 & -.11 & -.03 & .25 & --- & & & & & & & & \\
\hline 7. Work Importance & 3.32 & 1.06 & .34 & .34 & -.05 & .02 & .08 & .14 & $(.77)$ & & & & & & & \\
\hline 8. Work-Positive Affect & 3.57 & .65 & .33 & .34 & .19 & .11 & .26 & .04 & .16 & $(.89)$ & & & & & & \\
\hline 9. Work-Negative Affect & 1.56 & .50 & .06 & .03 & -.06 & .03 & .21 & .20 & .04 & -.25 & $(.83)$ & & & & & \\
\hline 10. Family Responsibility Demands & 3.81 & 1.24 & .07 & .06 & .28 & .26 & .30 & -.01 & .00 & .08 & .09 & $(.92)$ & & & & \\
\hline 11. Family Quantitative Demands & 36.31 & 21.95 & .04 & .04 & .32 & .27 & .02 & -.05 & -.08 & .05 & -.03 & .33 & --- & & & \\
\hline 12. Family Importance & 5.72 & .88 & .10 & .13 & .50 & .47 & .11 & .01 & -.06 & .11 & .00 & .18 & .22 & $(.78)$ & & \\
\hline 13. Family-Positive Affect & 3.78 & .71 & .07 & .12 & .47 & .32 & .16 & -.07 & -.08 & .53 & -.11 & .10 & .19 & .33 & $(.91)$ & \\
\hline 14. Family-Negative Affect & 1.50 & .51 & .05 & .02 & -.07 & .01 & .00 & .06 & .09 & -.07 & .42 & .25 & .05 & -.06 & -.34 & $(.87)$ \\
\hline
\end{tabular}

Note: $\mathrm{N}=675$. Correlations $>.07$ are significant at $\mathrm{p}<.05$. Numbers in parentheses are Cronbach's alpha coefficients. 
Table 2

Structural Model Findings for the Model of Engagement in Work and Family

\begin{tabular}{|c|c|c|c|c|c|c|c|c|c|c|c|c|c|c|}
\hline & \multicolumn{14}{|c|}{ Parameter Estimates } \\
\hline & \multicolumn{6}{|c|}{ Gammas } & \multicolumn{8}{|c|}{ Betas } \\
\hline Work Attention & $\begin{array}{l}\text { Work } \\
\text { Responsibility } \\
\text { Demands } \\
\quad .40^{* * * *}\end{array}$ & $\begin{array}{l}\text { Work } \\
\text { Time } \\
\text { Demands } \\
.15^{* * * *} *\end{array}$ & $\begin{array}{l}\text { Work } \\
\text { Importance } \\
\quad .47^{* * *}\end{array}$ & \begin{tabular}{l} 
Family \\
Responsibility \\
Demands \\
\multicolumn{1}{c}{ - }
\end{tabular} & $\begin{array}{l}\text { Family } \\
\text { Time } \\
\text { Demands } \\
\text {.- }\end{array}$ & $\begin{array}{l}\text { Family } \\
\text { Importance } \\
\text { - - }\end{array}$ & $\begin{array}{l}\text { Work } \\
\text { Attention } \\
\\
\text { - - }\end{array}$ & $\begin{array}{l}\text { Work } \\
\text { Absorption } \\
\text { - - }\end{array}$ & $\begin{array}{l}\text { Family } \\
\text { Attention } \\
\\
\text { - - }\end{array}$ & $\begin{array}{l}\text { Family } \\
\text { Absorption } \\
\text { - - }\end{array}$ & $\begin{array}{l}\text { Work } \\
\text { Positive } \\
\text { Affect } \\
\quad-\text { - }\end{array}$ & $\begin{array}{l}\text { Work } \\
\text { Negative } \\
\text { Affect } \\
\quad-\text { - }\end{array}$ & $\begin{array}{l}\text { Family } \\
\text { Positive } \\
\text { Affect } \\
-.05\end{array}$ & $\begin{array}{l}\text { Family } \\
\text { Negative } \\
\text { Affect } \\
-.02\end{array}$ \\
\hline Work Absorption & $.16^{* * * *}$ & .02 & $.43^{* * *}$ & - & - & - & - & - & - & - & - & - & $.19^{* * *}$ & $.10^{*}$ \\
\hline Family Attention & -- & -- & -- & .19 **** & $.15 * * *$ & $.55^{* * * *}$ & -. & -. & - & - & .03 & $-.15 * *$ & -- & - \\
\hline Family Absorption & -- & - & - & $.11^{*}$ & $.10^{*}$ & $.60^{* * *}$ & - & -- & -- & - & .07 & .07 & -- & -- \\
\hline Work Positive Affect & -- & - - & - & -- & - & -- & $.32 * * *$ & .11 & - & - & -- & -- & -- & - - \\
\hline Work Negative Affect & -- & - - & - & -- & - & -- & $.44 * * *$ & $-.34 * * *$ & -- & - & -- & -- & -- & -- \\
\hline Family Positive Affect & - - & - - & - - & - - & -- & - - & - - & - - & $.38 * * *$ & .10 & - - & - - & - - & - - \\
\hline $\begin{array}{l}\text { Family Negative } \\
\text { Affect }\end{array}$ & - - & - & - - & - & - - & - & - - & - & .15 & $-.19 *$ & - - & - - & - - & - - \\
\hline
\end{tabular}

Note: $\mathrm{N}=684$. All factor loadings and error variances are significant at the $\mathrm{p}<.001$ level. Coefficients are

completely standardized.

$* \mathrm{p}<.05 \quad * * \mathrm{p}<.01 \quad * * * \mathrm{p}<.001$ 
Table 3

Nested Model Tests

Comparison of Constrained Models to Target Structural Model Using Chi Square Difference Tests

\begin{tabular}{|c|c|c|c|c|c|c|}
\hline & & $\chi^{2}$ & d.f. & $\Delta \chi^{2}$ & $\Delta$ d.f. & p-value \\
\hline MM & Measurement Model & 615.36 & 210 & & & \\
\hline \multirow[t]{2}{*}{ STR } & Structural Model & 795.17 & 248 & 179.81 & 38 & $\mathrm{p}<.001$ \\
\hline & Constrained Models & & & & & \\
\hline M1 & $\begin{array}{l}\text { Dropped paths from Work and Family } \\
\text { Negative Affect to Family and Work } \\
\text { Engagement Respectively }\end{array}$ & 809.97 & 252 & 14.80 & 4 & $\mathrm{p}<.01$ \\
\hline M2 & $\begin{array}{l}\text { Dropped paths from Work and Family } \\
\text { Positive Affect to Family and Work } \\
\text { Engagement Respectively }\end{array}$ & 817.82 & 252 & 22.40 & 4 & $\mathrm{p}<.001$ \\
\hline M3 & $\begin{array}{l}\text { Dropped paths from Work and Family } \\
\text { Demands to Work and Family } \\
\text { Engagement }\end{array}$ & 957.55 & 256 & 162.38 & 8 & $\mathrm{p}<.001$ \\
\hline M4 & $\begin{array}{l}\text { Dropped paths from Work and Family } \\
\text { Importance to Work and Family } \\
\text { Engagement }\end{array}$ & 1141.78 & 252 & 346.61 & 4 & $\mathrm{p}<.001$ \\
\hline M5 & $\begin{array}{l}\text { Dropped paths from Family Affect to } \\
\text { Work Engagement }\end{array}$ & 814.82 & 252 & 19.65 & 4 & $\mathrm{p}<.001$ \\
\hline M6 & $\begin{array}{l}\text { Dropped paths from Work Affect to } \\
\text { Family Engagement }\end{array}$ & 814.7 & 252 & 19.53 & 4 & $\mathrm{p}<.001$ \\
\hline M7 & $\begin{array}{l}\text { Dropped paths from Work Engagement to } \\
\text { Work Affect }\end{array}$ & 993.89 & 252 & 198.72 & 4 & $\mathrm{p}<.001$ \\
\hline M8 & $\begin{array}{l}\text { Dropped paths from Family Engagement } \\
\text { to Family Affect }\end{array}$ & 995.26 & 252 & 2.09 & 4 & $\mathrm{p}<.001$ \\
\hline
\end{tabular}


Table 4

Multiple Group Analyses

Tests of Invariance between Men and Women in the Structural Model of Engagement in Work and Family

\begin{tabular}{|c|c|c|c|}
\hline & Model & Goodness of Fit & Test of Hypothesis \\
\hline M1 & Equal Factor Pattern & $\begin{array}{l}\chi^{2}(496)=1048.09 \mathrm{p}<.001 \\
\text { CFI }=.93 \\
\text { RMSEA }=.057 \\
\text { SRMR }=.066\end{array}$ & \\
\hline M2 & Equal Factor Loadings & $\chi^{2}(508)=1064.03$ & $\begin{array}{l}\text { M2-M1 } \\
\Delta \chi^{2}(12)=15.94 \\
\mathrm{p} \cong .19\end{array}$ \\
\hline M3 & $\begin{array}{l}\text { Equal Factor Loadings and equal Error } \\
\text { Variances }\end{array}$ & $\chi^{2}(532)=1146.78$ & $\begin{array}{l}\text { M3-M2 } \\
\Delta \chi^{2}(24)=82.75 \\
p<.001\end{array}$ \\
\hline M4 & $\begin{array}{l}\text { Equal Factor Loadings and equal Gamma } \\
\text { parameter estimates }\end{array}$ & $\chi^{2}(520)=1087.34$ & $\begin{array}{l}\mathrm{M} 4-\mathrm{M} 2 \\
\Delta \chi^{2}(12)=23.31 \\
\mathrm{p}<.03\end{array}$ \\
\hline M5 & $\begin{array}{l}\text { Equal Factor Loadings and equal Beta } \\
\text { parameter estimates }\end{array}$ & $\chi^{2}(524)=1111.94$ & $\begin{array}{l}\text { M5-M2 } \\
\Delta \chi^{2}(16)=47.91 \\
\mathrm{p}<.001\end{array}$ \\
\hline M6 & $\begin{array}{l}\text { Equal Factor Loadings and equal Phi } \\
\text { estimates }\end{array}$ & $\chi^{2}(527)=1092.22$ & $\begin{array}{l}\text { M6-M2 } \\
\Delta \chi^{2}(19)=28.19 \\
\mathrm{p} \cong .080\end{array}$ \\
\hline M7 & $\begin{array}{l}\text { Equal Factor Loadings, equal Phi } \\
\text { estimates, and equal Psi estimates }\end{array}$ & $\chi^{2}(547)=1163.01$ & $\begin{array}{l}\text { M7-M6 } \\
\Delta \chi^{2}(20)=7.79 \\
\mathrm{p}<.001\end{array}$ \\
\hline
\end{tabular}

Note: $\quad \mathrm{N}_{\mathrm{M}}=219 ; \mathrm{N}_{\mathrm{W}}=464$ 
Table 5

Mean Differences for Latent Variables by Gender in the Model of Engagement in Work and Family

\begin{tabular}{lc}
\hline Latent Factor & Change in Mean \\
\hline Work Responsibility Demands & $.13(.09)$ \\
Work Time Demands & $5.12(1.19)^{* * *}$ \\
Work Importance & $.20(.09)^{*}$ \\
Family Responsibility Demands & $-.11(.11)$ \\
Family Time Demands & $-6.92(1.70)^{* * *}$ \\
Family Importance & $-.02(.06)$ \\
Work Attention & $-.13(.10)$ \\
Work Absorption & $-.36(.10)^{* * *}$ \\
Family Attention & $-.25(.08)^{* *}$ \\
Family Absorption & $-.14(.10)$ \\
Work Positive Affect & $-.12(.05)^{*}$ \\
Work Negative Affect & $.17(.05)^{* *}$ \\
Family Positive Affect & $-.16(.06)^{* *}$ \\
Family Negative Affect & $.06(.05)$ \\
\hline
\end{tabular}

Note: Standard errors are in parentheses. Means of factors for Women are fixed to zero. N(women)=464, $\mathrm{N}($ Men $)=219$.

$* \mathrm{p}<.05 \quad * * \mathrm{p}<.01 \quad * * * \mathrm{p}<.001$ 